\title{
MANUFACTURE AND COMPOSITIONAL ANALYSIS OF SILICON NITRIDE COMPOSITES WITH DIFFERENT CARBON ADDITIONS
}

Carbon black and graphite nano/micrograins and sintering additives $\left(\mathrm{Al}_{2} \mathrm{O}_{3}\right.$ and $\left.\mathrm{Y}_{2} \mathrm{O}_{3}\right)$ were added to silicon nitride starting powder. These mixtures were mechanochemically activated several hours in a planetary type alumina ball-mill in order to achieve a homogenous mass. As an alternative to nano- and micrograins, carbon fibres were added to carbon free silicon nitride batches. After dry pressing of rectangular bars sinter-HIP was applied. Structural, morphological and compositional analyses were performed on as-prepared samples. Bending strength and elastic modulus were found to be influenced by amount of carbon black and graphite introduced in silicon nitride matrix.

\section{Introduction}

Ceramics based on silicon nitride are well-known as low density materials with high strength and toughness. With this combination of properties silicon nitride based ceramics are an ideal candidate for several structural applications, even at high temperatures. Lately, by in-situ tailoring the microstructure, new observations were performed on structural and morphological development on silicon nitride ceramics in order to understand the governing principles of sintering processes [1, 2]. In this way, through formation of tough interlocking microstructure mechanical properties may be improved. Intensive research work has been done to improve physical and mechanical properties of silicon nitride ceramics through nanocomposite processing [3]. To increase the fracture toughness, incorporation of various energy-dissipating components into ceramic matrices have been performed $[4,5]$.

These components can be introduced in whisker, platelets, particles or fibre forms. A low cost silicon carbide-silicon nitride nanocomposite processing route has been reported by Hnatko et al [6]. In this case, the formation of bulk silicon nitride based nanocomposite is realized by carbothermal reduction of $\mathrm{SiO}_{2}$ by carbon in the $\mathrm{Y}_{2} \mathrm{O}_{3}-\mathrm{SiO}_{2}$ system at the sintering temperature, with $\mathrm{SiC}$ nanoparticles as result. Although, the mechanical properties of as-prepared samples should be further optimized, this process seems to be a perspective choice for silicon nitride-silicon carbide nanocomposite production [7]. In this paper silicon nitride based nanocomposites were prepared through carbon black addition by mechanochemical synthesis and hot isostatic pressing (HIP). Results about structural, morphological and compositional measurements are presented.

\section{Experimental method}

Details about sample preparation can be followed in Table 1 . The compositions of the starting powder mixtures of the four materials were the same: 90 wt.\% $\mathrm{Si}_{3} \mathrm{~N}_{4}$ (Ube SN-ESP), 4 wt.\% $\mathrm{Al}_{2} \mathrm{O}_{3}$, and 6 wt.\% $\mathrm{Y}_{2} \mathrm{O}_{3}$. In addition to batches carbon black (Taurus Carbon black, N330, average particle size between $\sim 50-100 \mathrm{~nm}$ ), graphite (Aldrich, synthetic, average particle size 1-2 $\mu \mathrm{m}$ ) and carbon fibre (Zoltek, PX30FBSWO8) were added. The powder mixtures were milled in ethanol in a planetary type alumina ball mill for 150 hours. The samples were compacted by dry pressing at $220 \mathrm{MPa}$. Samples from 644 and 645 batches were collected during milling process after several stops. Carbon fibres were added to mixtures only before dry pressing (samples 629 from Table 1.) Samples were passed to FTIR examinations. Infrared absorption spectra were taken by BOMEM MB-102 FTIR spectrophotometer equipped with a deutero-triglicine-sulfate detector, at a resolution of $4 \mathrm{~cm}^{-1}$, in the range of $400-4000 \mathrm{~cm}^{-1} ; 2 \mathrm{mg} / \mathrm{g} \mathrm{KBr}$ pellets were used. The materials were sintered at $1700{ }^{\circ} \mathrm{C}$ in high purity nitrogen by a two-step sinter-HIP method using BN embedding powder. First, some of the samples were sintered without applying pressure. In second step, the samples from first sintering step (serving as reference samples) were re-introduced in the HIP, together with the rest of examined samples. Then, pressure of $20 \mathrm{bar}$ was applied for one hour.

The dimensions of the as-sintered specimens were approximately $3.5 \times 5 \times 50 \mathrm{~mm}$.

After sintering the weight-gain values were determined. The density of the as-sintered materials was measured by the Archimedes method. To identify the crystalline phases X-ray diffraction of $\mathrm{Cu}$

\footnotetext{
* ${ }^{1}$ Dr. Csaba Balázsi, ${ }^{1}$ Ing. Ferenc Wéber, ${ }^{2}$ Dr. Zsolt Kasztovszky

${ }^{1}$ Ceramics and Refractory Metals Laboratory, Research Institute for Technical Physics and Materials Science, Hungarian Academy of Sciences, 1121 Budapest, Konkoly-Thege út 29-33, E-mail: balazsi@mfa.kfki.hu, weber@mfa.kfki.hu.

${ }^{2}$ Department of Nuclear Research, Institute of Isotope and Surface Chemistry, Chemical Research Center, POB 77, H-1525 Budapest, Hungary, Email: kzsolt@alpha0.iki.kfki.hu
} 
$\mathrm{K} \alpha$ radiation was applied. Morphology of the solid products was studied by scanning electron microscopy, with a JEOL-25 microscope. The elastic modulus and the four-point bend strength were determined by a bending test with spans of $40 \mathrm{~mm}$ and $20 \mathrm{~mm}$. Three-point strength was measured on broken pieces with a span of $20 \mathrm{~mm}$.

The compositional analysis of sintered samples was performed by prompt-gamma activation analysis (PGAA) which is based on the detection of prompt gamma rays originating from $(n, \gamma)$ reaction, and gives average elemental composition of the total volume of the sample [8].

The composition of starting powder mixtures.

Table 1.

\begin{tabular}{|c|ccc|c|c|c|}
\hline \multirow{2}{*}{ Batch } & \multicolumn{3}{|c|}{ Composition, wt\% } & \multicolumn{3}{|c|}{ Added carbon } \\
\cline { 2 - 7 } & $\mathrm{Si}_{3} \mathrm{~N}_{4}$ & $\mathrm{Al}_{2} \mathrm{O}_{3}$ & $\mathrm{Y}_{2} \mathrm{O}_{3}$ & $\begin{array}{c}\text { carbon } \\
\text { black }\end{array}$ & graphite & $\begin{array}{c}\text { carbon } \\
\text { fibre }\end{array}$ \\
\cline { 3 - 7 } & & & & $\begin{array}{c}\mathrm{C}_{\mathrm{C} / \mathrm{Si}_{3} \mathrm{~N}_{4}} \\
\text { molar ratio }\end{array}$ & $\begin{array}{c}\mathrm{C}^{2} \mathrm{Si}_{3} \mathrm{~N}_{4} \\
\text { molar ratio }\end{array}$ & $\begin{array}{c}\text { wt\% to } \\
\text { batch }\end{array}$ \\
\hline 642 & 90 & 4 & 6 & - & - & - \\
\hline 644 & 90 & 4 & 6 & 3 & - & - \\
\hline 645 & 90 & 4 & 6 & - & 3 & - \\
\hline 629 & 90 & 4 & 6 & - & - & 1 \\
\hline
\end{tabular}

\section{Results and discussion}

Infrared spectroscopy measurements are presented in Fig. 1. Samples extracted from 644 batch during long duration milling experiment can be followed in Fig. 1c, Fig. 1d and Fig. 1e. Infrared spectra of yttria and alpha silicon nitride starting powders are presented in Fig. 1a and Fig. 1b. iN yttria powder spectra we can distinguish two characteristic peaks at 606 and $631 \mathrm{~cm}^{-1}$. The mixture of powders mechanically activated for 1 hour (Fig. 1c) is characterized mainly by alpha silicon nitride vibration modes (as in Fig. 1b). O-H stretching modes at $3432 \mathrm{~cm}^{-1}$ and $\mathrm{O}-\mathrm{H}$ bending at $1634 \mathrm{~cm}^{-1}$ can be found in infrared spectra.

These vibrations are assigned with $\mathrm{N}-\mathrm{H}$ vibrations in case of inert atmosphere working conditions. At the end of mechanical activation (Fig. 1d) as a result we have a mixture with dominant alpha silicon nitride vibration modes. The vibration modes considered to be Si-N at $600 \mathrm{~cm}^{-1}$ and yttria at $640 \mathrm{~cm}^{-1}$ appeared. At the end of activation $\mathrm{O}-\mathrm{H}$ bonds disappeared from spectra. After oxidation at $800^{\circ} \mathrm{C}$ for 2 hours (Fig. 1e) peaks characteristic to alpha silicon nitride and yttria can be observed on infrared spectra. Alumina which has a broad band at $798 \mathrm{~cm}^{-1}$ (not presented in figure) and presents $4 \mathrm{wt} \%$ of the mixture can not be seen and has no substantial effect on the spectra of mixtures.

We found the same characteristic vibrations in the case of preparations with graphite (batch 645). After performing the mechanical activation of powder mixtures, rectangular samples were obtained

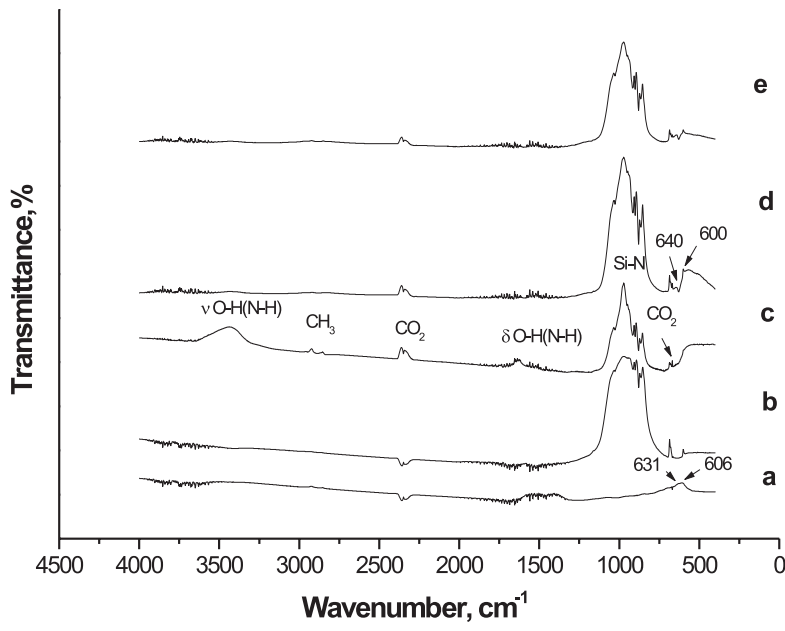

Fig. 1 FTIR spectra of starting materials and milling products (batch 644); $a-Y_{2} O_{3}$ starting sintering additive powder; $b-\alpha-\mathrm{Si}_{3} \mathrm{~N}_{4}$ starting powder; $c$ - Resulting mixture after Ih activation; $d$ - Resulting mixture after 150 h activation; $e$ - Resulting mixture after $150 \mathrm{~h}$ activation and oxidation at $800{ }^{\circ} \mathrm{C}$ for $2 \mathrm{~h}$.

by dry pressing at $220 \mathrm{MPa}$. The as-obtained samples were oxidized at different temperatures. Oxidizing at different temperatures resulted in samples with different carbon content as presented in Fig. 2. An interesting remark can be added to observations presented in Fig. 2. The behavior of nanocrystalline carbon black and graphite added to silicon nitride matrix was found to be sharply different regarding the oxidation process.

From $450{ }^{\circ} \mathrm{C}$ up to $600{ }^{\circ} \mathrm{C}$ the carbon black content has a decreasing tendency, at $600{ }^{\circ} \mathrm{C}$ was $0.4 \mathrm{wt} \%$. At this stage, the graphite content is around $10 \mathrm{wt} \%$. From this point the graphite content has also a decreasing tendency with increasing tempera-

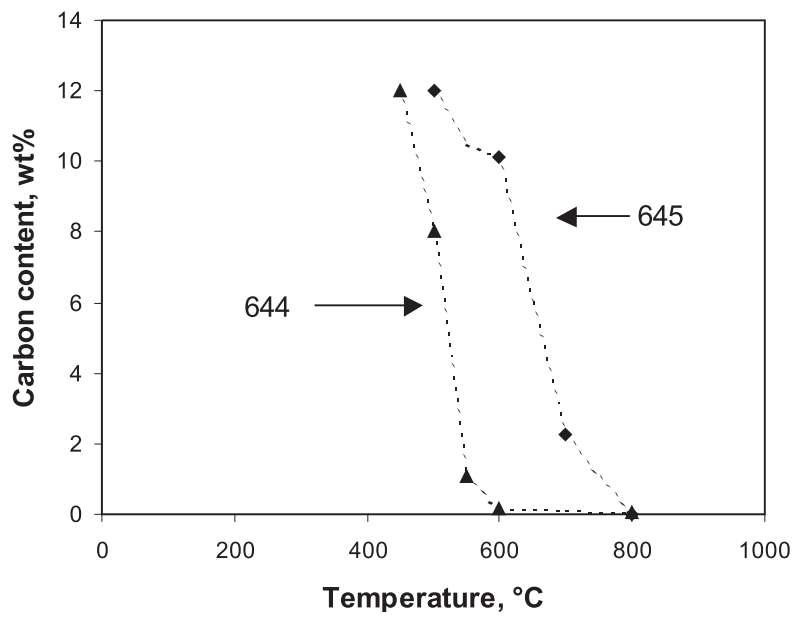

Fig. 2 Samples with different carbon contents after oxidation in atmosphere. In each point the average value of four samples is presented. 


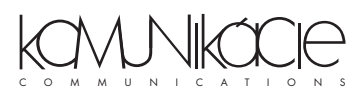

ture. Continuing the oxidation process above $800{ }^{\circ} \mathrm{C}$, according to weight losses, we obtained a carbon free structure.

Morphological study was performed after two-step sintering by scanning electron microscopy. In Fig. 3a. the microstructure of a reference sample (642) consisting of equiaxial grains can be seen. The structure of the sample characterized by high content of nanocrystalline carbon black is sharply different, the grains are connected through elongated necks (Fig. 3b). Huge sticking grains can be also observed, which developed during a milling process. On the microstructure of sample with no carbon content, derived from oxidation at $800{ }^{\circ} \mathrm{C}$ of carbon black containing sample, more developed grains can be observed (Fig. 3c).

Similarly developed grains and sticking tendency can be followed in the case of a sample with high graphite content (Fig. 3d). can be foreseen that the fracture, crack propagation in this sample involves a combination of intra- and intergranular path which needs higher energy demand. As regards the samples from batch 644 however, the sticking grains of $10-30 \mu \mathrm{m}$ in size (Fig. $4 \mathrm{~b}$, and $4 c)$ act as inclusions in structure and induce intergranular fractures, which requires less energy input.

In Fig. 5a and Fig. 5b carbon fibers pulled out from the matrix and embedded in the matrix can be seen. A deterioration of carbon fibers, cavities developing on the surface of fibers should be noticed.

Relation between apparent density of samples containing carbon (644 and 645) and reference (642) carbon free sample and modulus of elasticity after sintering are presented in Fig. 6.

A higher apparent density and higher modulus than samples with carbon content characterize the 642 reference samples. Samples

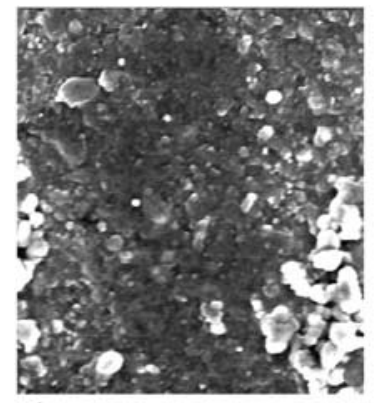

a)

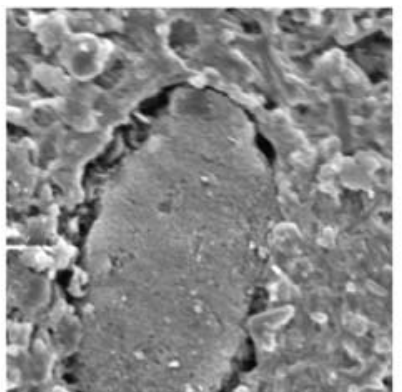

b)

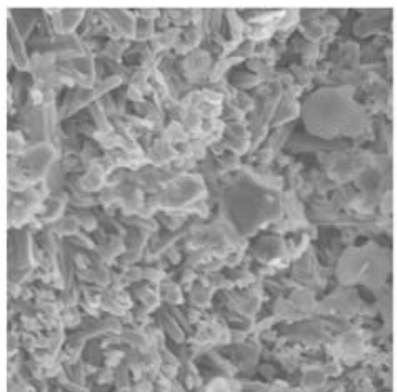

c)

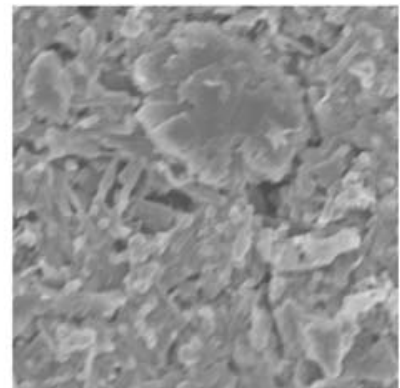

d)

10 um

Fig. 3 Scanning electron micrographs of the surface of the samples after two-step sintering process. a - reference sample (642). $b$ - sample from batch 644, with $11,9 \mathrm{wt} \%$ carbon content after oxidation at $450{ }^{\circ} \mathrm{C}$ (as in Fig. 2) c - sample from batch 644, with no carbon content after oxidation at $800^{\circ} \mathrm{C}$ (as in Fig. 2). $d$ - sample from batch 645 , with $12 \mathrm{wt} \%$ graphite content after oxidation at $500{ }^{\circ} \mathrm{C}$ (as in Fig. 2).

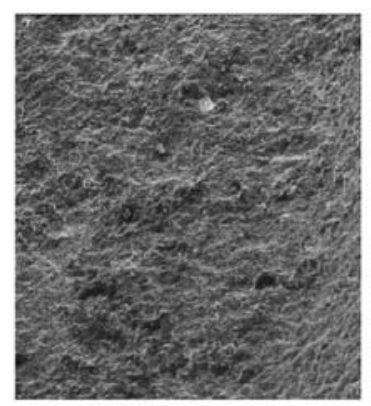

a)

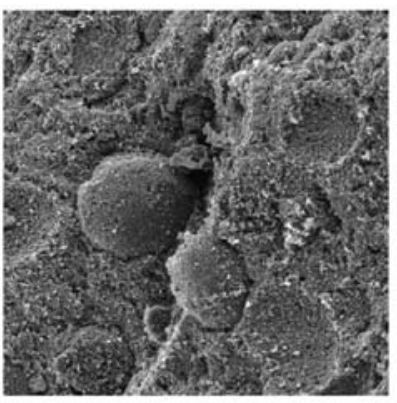

b)

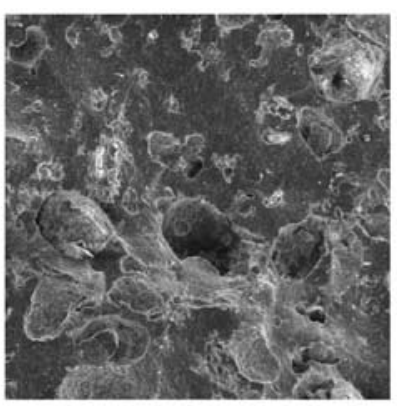

c)

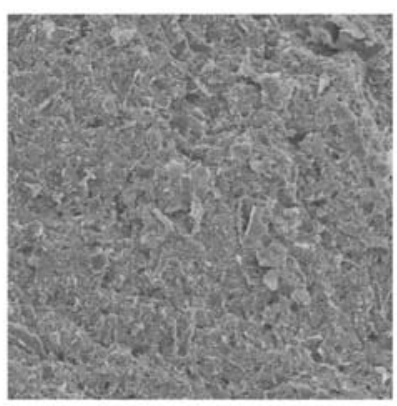

d)

100um-

Fig. 4 Scanning electron micrographs of fracture surface of the samples after two-step sintering process. $a$ - reference sample (642). $b$ - sample from batch 644, with 11,9 wt\% carbon content after oxidation at $450{ }^{\circ} \mathrm{C}$ (as in Fig. 2) c - sample from batch 644, with no carbon content after oxidation at $800^{\circ} \mathrm{C}$ (as in Fig. 2). $d$ - sample from batch 645 , with $12 \mathrm{wt} \%$ graphite content after oxidation at $500{ }^{\circ} \mathrm{C}$ (as in Fig. 2).

A morphological study was made on fractured surfaces as shown in Fig. 4. In Fig. 4a the homogenous microstructure of a reference sample (642) can be seen. From these micrographs
644 (nanocrystalline carbon black) have higher modulus values than samples with graphite (645). Linearly fitted straight line 176 were added to Fig. 6 from Ref. 9. 


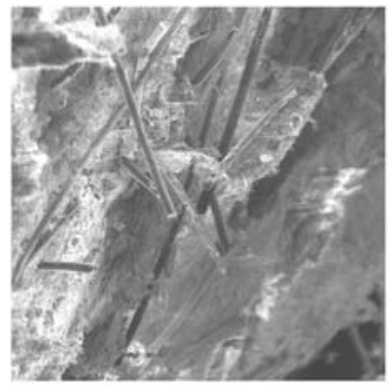

a)

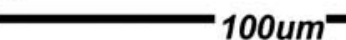

b)

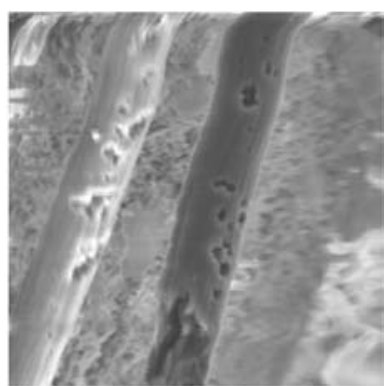

Fig. 5 Scanning electron micrographs of fracture surface of the carbon fiber containing samples (629) after sintering process. a -fibers pulled out from matrix. $b$ - fibers embedded in matrix, presenting deterioration (holes) on surface.

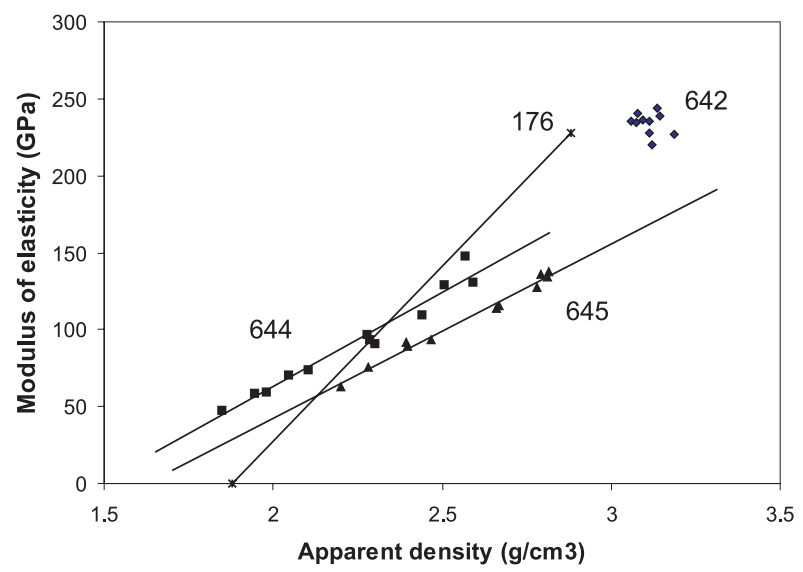

Fig. 6 Relation between apparent density and modulus of elasticity after sintering. 644 and 645 samples containing carbon, 642 and 176 carbon free samples.

These lines were produced to study partial and final sintering processes. From Fig. 6 it seems that carbon content variation has the same role as partial sintering. The same curves (regression lines) as in the case of line 176, but different gradients can be observed at samples 644 and 645 . The linear regression line 176 has the intersection with $x$ axis is at 1.88 value. As conclusion can be drawn that samples 644 at low densities have higher modulus values than the reference samples. This means that at the initial stage of sintering a certain amount of carbon addition has a beneficial role to the modulus of elasticity. This tendency is maintained till 2.338 value obtained from intersection of regression lines 176 and 644 . Above this value, although modulus of batches 644 and 645 have an increasing tendency, compared with reference 176 carbon content has a detrimental role to modulus.

In Fig. 7a the x-ray diffractogram of a reference sample can be seen after sintering at $1700^{\circ} \mathrm{C}$, nitrogen atmosphere and without applying pressure. The structure consists of $\beta-\mathrm{Si}_{3} \mathrm{~N}_{4}$ and $\alpha-\mathrm{Si}_{3} \mathrm{~N}_{4}$.

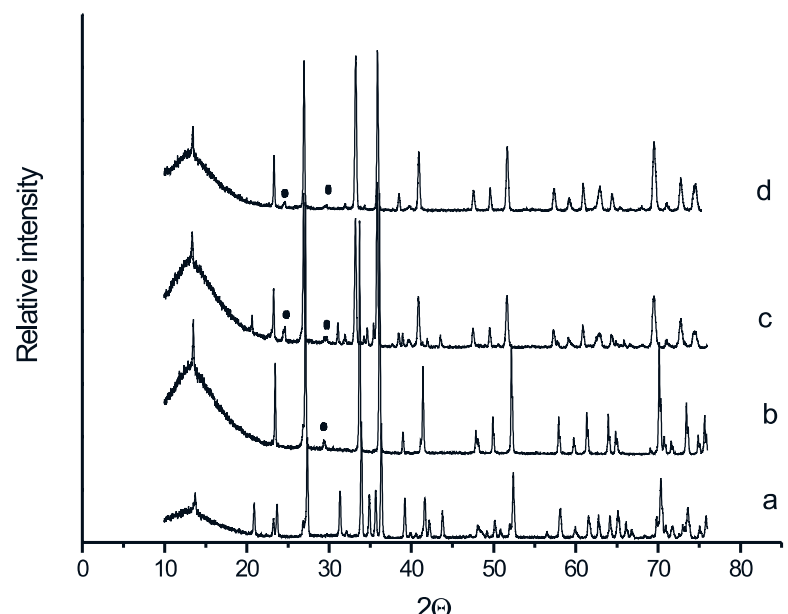

Fig. 7 X-ray diffractograms of one and two step sintered samples; $a$ - reference sample (642) sintered without pressure; $b$ - reference sample (642) sintered under pressure; $c$ - nanocrystalline carbon added (644) sample first step sintered; $d$ - carbon added sample (644)

after two-step sintering. Black points mark the new phase(s).

After the second sintering step (Fig. 7b) mostly the reflection of $\beta-\mathrm{Si}_{3} \mathrm{~N}_{4}$ can be recognized. At $d=0.3041 \mathrm{~nm}$ however, an unidentified peak has appeared. At this stage of study identification of this peak is still uncertain, however this reflection is close to $\delta-\mathrm{Y}_{2} \mathrm{Si}_{2} \mathrm{O}_{7}$ reflections. In Fig. 7c the reflections of sample from batch 644 can be seen after first sintering step. The structure consists of $\beta-\mathrm{Si}_{3} \mathrm{~N}_{4}$, $\alpha-\mathrm{Si}_{3} \mathrm{~N}_{4}$ and a minor contribution of $\mathrm{SiC}$ (JCPDS 31-1231) can be observed. In addition to this reflections at $d=0.3613 \mathrm{~nm}$ and $d=0.3041 \mathrm{~nm}$ can be observed, which may be attributed to $\delta-\mathrm{Y}_{2} \mathrm{Si}_{2} \mathrm{O}_{7}$ reflections. After the second sintering step the structure is converting to $\beta-\mathrm{Si}_{3} \mathrm{~N}_{4}$ phase, but retains some of the possible $\delta-\mathrm{Y}_{2} \mathrm{Si}_{2} \mathrm{O}_{7}$ reflections $(d=0.3613 \mathrm{~nm}$ and $d=0.3041 \mathrm{~nm})$ and some of the $\alpha-\mathrm{Si}_{3} \mathrm{~N}_{4}$ reflections $(d=0.2259 \mathrm{~nm}, 0.2619 \mathrm{~nm}$ and $0.280 \mathrm{~nm}$ )

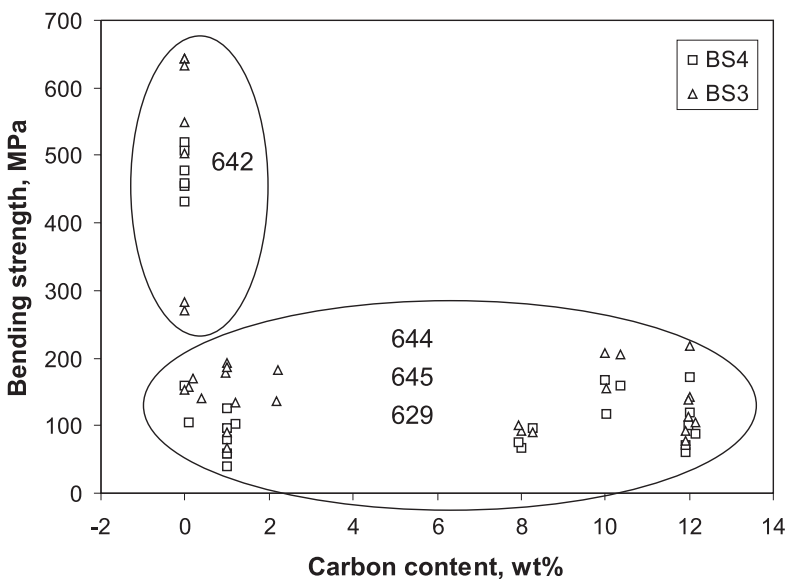

Fig. 8 Relation between carbon content and four point bending strength (BS4) and three point bending strength (BS3). Carbon contents for samples 644 and 645 resulted from oxidation process as in Fig. 3. Samples 629 are characterized by 1 wt\% carbon content as in Table 1. 
A comprehensive view about the carbon content effect to strength can be seen in Fig. 8. Samples with added carbon (629, 644, 645) present lower values for strength as compared with 642 reference samples. vibration modes. Carbon addition has the same role as partial sintering. In the initial stage of sintering the carbon addition has a beneficial role to the modulus of elasticity. Above a certain value however, carbon content has a detrimental role to the modulus. The

The composition of sintered samples

Table 2

\begin{tabular}{|c|c|c|c|c|c|c|c|c|c|c|c|}
\hline \multicolumn{5}{|c|}{ Reference sample from batch 642} & \multicolumn{5}{|c|}{ Carbon black-silicon nitride composite } \\
\hline Z & El & M & atomic $\%$ & wt $\%$ & rel. unc $\%$ & Z & El & M & atomic \% & wt\% & rel. unc \% \\
\hline 1 & H & 1.01 & 0 & $<\mathbf{0 . 0 0 1}$ & & 1 & H & 1.01 & 0.438 & $\mathbf{0 . 0 2 3}$ & 7.9 \\
\hline 5 & B & 10.8 & 0.036 & $\mathbf{0 . 0 1 9}$ & 0.9 & 5 & B & 10.8 & 0.13 & $\mathbf{0 . 0 7 3}$ & 0.9 \\
\hline 7 & N & 14 & 56.05 & $\mathbf{3 7 . 6 2}$ & 1.9 & 6 & C & 12 & 23.33 & $\mathbf{1 4 . 6 7 7}$ & 12.8 \\
\hline 13 & $\mathrm{Al}$ & 27 & 1.588 & $\mathbf{2 . 0 5 3}$ & 2.9 & 7 & $\mathrm{~N}$ & 14 & 38.21 & $\mathbf{2 8 . 0 2 8}$ & 2.3 \\
\hline 14 & $\mathrm{Si}$ & 28.1 & 41.16 & $\mathbf{5 5 . 3 8}$ & 2.3 & 13 & $\mathrm{Al}$ & 27 & 12.03 & $\mathbf{1 6 . 9 9 5}$ & 2.3 \\
\hline 39 & $\mathrm{Y}$ & 889 & 1.154 & $\mathbf{4 . 9 1 5}$ & 1.9 & 14 & $\mathrm{Si}$ & 28.1 & 25.15 & $\mathbf{3 6 . 9 9 8}$ & 2.6 \\
\hline & & & & & 39 & $\mathrm{Y}$ & 889 & 0.678 & $\mathbf{3 . 1 5 6}$ & 2.4 \\
\hline
\end{tabular}

The compositions of sintered samples were determined by prompt-gamma activation analyses. Comparing the $\mathrm{Si} / \mathrm{N}$ mass fractions of the reference sample and the composite sample (sample from batch 644 , with $11.9 \mathrm{wt} \%$ carbon content after oxidation at $450{ }^{\circ} \mathrm{C}$ ) the effect of carbon content on the complex sintering process is observed, namely in the presence of carbon, the $\mathrm{Si} / \mathrm{N}$ mass fraction has decreased. Because of high relative uncertainty the amount of oxygen was neglected.

\section{Conclusion}

Preparation of $\mathrm{C} / \mathrm{Si} 3 \mathrm{~N} 4$ nanocomposites was performed. The milling product of added carbon black and graphite could be characterized by the same structural characteristics, nearly by the same morphological studies showed the sticking tendency of powders. Carbon added samples are characterized by lower bending strengths than reference monolithic samples. During a pressureless sintering step the structure retains the $\alpha-\mathrm{Si}_{3} \mathrm{~N}_{4}$ phase, after the second sintering step the alpha silicon nitride to beta silicon nitride phase transformation was completed. The $\mathrm{Si} / \mathrm{N}$ fraction decreased during sintering process because of the presence of carbon.

\section{Acknowledgements}

Csaba Balázsi thanks for OTKA Postdoctoral Research Grant (D38478), János Bolyai Research Grant and Hungarian State Eötvös Fellowhsip. Support from OTKA T043704 is greatly acknowledged.

\section{References:}

[1] SHEN, Z., ZHAO, Z., PENG, H., NYGREN, M.: Nature, Vol. 417, 16 May 2002, 266.

[2] THOMPSON, D. P.: Nature, Vol. 417, 16 May 2002, 237.

[3] BHADURI, S., BHADURI, S. B.: JOM, January (1998) 44-50.

[4] STERNITZKE, M.: Journal of European Ceramic Society, 17 (1997) 1061-1082.

[5] DJURICIC, B., LACOM, W., KRUMPEL, G., BRABETZ, M.: Nano-Science, It's time 02/02, 1-8.

[6] HNATKO, M., SAJGALIK, P., LENCES, Z., MONTEVERDE, F., DUSZA, J., WARBICHLER, P., HOFER, F.: Key Eng. Mat. Vols 206-213 (2002) 1061.

[7] BALÁZSI, CS., WÉBER, F., ARATÓ, P.: Mat.-wiss. u. Werkstofftech, 34 (2003) 332-337.

[8] KASZTOVSZKY, ZS., RÉVAY, ZS., BELGYA, T., FAZEKAS, B., ÖSTÖR, J., MOLNÁR, G. L., MOLNÁR, G., BOROSSAY, J. J. Anal. At. Spectrom., 14 (1999) 593-596.

[9] ARATÓ, P., BESENYEI, E., KELE, A., WÉBER, F.: J. Mat. Sci. 30 (1995) 1863. 